\title{
CARACTERIZAÇÃO DAS TENSÕES DE ESCOAMENTO DO AÇO ELÉTRICO DE GRÃO ORIENTADO EM ALTAS TEMPERATURAS*
}

\section{Resumo}

Géssica Seara Faria ${ }^{1}$ Karine Morais D'Assunção ${ }^{2}$ Luxmar Alves Xavier ${ }^{3}$

Na produção de bobinas laminadas a quente, além da força aplicada pelos cilindros de laminação sobre a tira para promover a redução de espessura, o material é também submetido a tensões avante e a ré, durante o seu bobinamento e desbobinamento, que devem ser inferiores ao limite de escoamento do material conforme sua temperatura de trabalho. Este estudo trata da caracterização das tensões de escoamento do aço elétrico de grão orientado com 3,2 \% de silício em altas temperaturas. A necessidade do estudo surgiu devido a ocorrência do defeito estiramento durante processo de laminação a quente de acabamento em laminadores reversíveis tipo Steckel, defeito este que consiste no estreitamento da largura da tira em regiões localizadas. Isto acontece em função do desconhecimento do limite de escoamento real do material nas temperaturas de trabalho. Os ensaios foram realizados em máquina de tração a quente, em temperaturas previamente determinadas. Através dos resultados dos ensaios, foram determinadas as curvas tensão x deformação do aço e valores limitantes de tensão conforme variação da temperatura, para que o processo não exceda o limite de escoamento do material.

Palavras-chave: Laminação a quente; Limite de escoamento; Ensaio de tração em alta temperatura.

\section{CHARACTERIZATION OF THE YIELD POINT OF GRAIN ORIENTED SILICON STEEL AT HIGH TEMPERATURES}

\section{Abstract}

In the production of hot rolled strip, in addition to the force applied by the laminating rolls on the strip, to promote the reduction in thickness, the material is also subjected to fore and aft tension during its winding and unwinding, which should be less than yield strength of the material according to its working temperature. This study is about the characterization of the yield strengths of the grain oriented electrical steel with $3.2 \%$ silicon, processed at high temperatures. The need to this study arose from the occurrence of the defect narrowring during the hot rolling process of finishing in reversible rolling, type Steckel, this defect consisting of narrowing the width of the strip in localized regions. This is due to the lack of knowledge of the real yield strength of the material at high temperatures. The tests were performed on hot tensile machine at predetermined temperatures. From the results of the tests, the curves stress $x$ strain were determined and limiting stress values according to the temperature's range, therefore the process does not exceed the yield point of the steel.

Keywords: Hot rolling; Yield strength; Tensile test at high temperature.

1 Graduanda em Engenharia Metalúrgica, Centro Universitário do Leste de Minas Gerais - Unileste, Coronel Fabriciano, Minas Gerais, Brasil.

2 Graduanda em Engenharia Mecatrônica, Universidade Federal de São João Del Rei - Campus Alto Paraopeba, Ouro Branco, Minas Gerais, Brasil.

3 Bacharel em Engenharia Metalúrgica, Supervisor, Laboratório de Testes Mecânicos, Usiminas S/A Ipatinga, Minas Gerais, Brasil. 


\section{INTRODUÇÃO}

O laminador tipo Steckel possui apenas uma cadeira de laminação posicionada entre dois fornos em caixa, providos de um tambor rotativo para bobinar a tira durante o processo de laminação. A perda de calor durante o processo de laminação de acabamento é minimizada pelo acondicionamento da tira nos fornos posicionados na entrada e na saída do laminador durante a execução do passe [1,2]. Entretanto, há uma diferença considerável de temperatura ao longo do comprimento da tira, uma vez que as extremidades perdem mais calor durante o processo devido a maior exposição ao ambiente, quando comparadas a região central. Portanto, os mecanismos de amolecimento da estrutura da região central da tira serão intensificados, resultando em menor resistência a deformação [3].

O atrito entre os cilindros de laminação e a superfície do metal é de grande importância no processo, uma vez que é necessária uma força de atrito para puxar a tira entre os cilindros. Entretanto um atrito alto resulta em grandes cargas de laminação e uma tendência ao surgimento de defeitos. A presença de tração no plano da placa pode reduzir a carga de laminação, tração esta que é controlada pela combinação das tensões avante e a ré. A tensão a ré pode ser produzida por controle da velocidade da desbobinadeira em relação velocidade dos cilindros, e a tensão avante pode ser criada pelo controle da bobinadeira. A adição da tensão avante e da tensão a ré juntas reduz a área sobre a curva, portanto, a pressão dos cilindros é reduzida na proporção direta à tração no plano da tira. Isso resulta num menor desgaste dos cilindros e aumenta a uniformidade da espessura ao longo da largura da tira [4]. Porém se a as tensões avante e a ré forem muito intensas, as condições de tração no plano da placa são também intensificadas, o que pode levar ao aparecimento de um defeito conhecido como estiramento da tira, que consiste no estreitamento da largura da tira em regiões localizadas.

As tensões avante e a ré aplicadas pelas bobinadeiras, permanecem constantes durante todo o processo de laminação a quente no laminador Steckel. Dessa forma a temperatura é o principal fator que pode causar variação aleatória da tensão durante a deformação. A região central da tira, que na maioria das vezes é a região que apresenta temperatura mais alta, é também a região com maior susceptibilidade a ocorrência do defeito estiramento, uma vez que terá o seu limite de escoamento reduzido em relação às demais regiões.

Estudos anteriores realizados pela empresa Aperam South America, que produz o aço elétrico de grão orientado (GO) com 3,2 \% de silício, determinaram os limites de escoamento conforme variação da temperatura [5]. Entretanto, ao longo dos anos foram realizadas sutis modificações na composição química deste aço por implicações do processo, e não houve desde então nenhuma avaliação com o objetivo de detectar a influência que estas alterações poderiam causar no processo a quente. Com o aparecimento do defeito estiramento foi detectada a necessidade de novos estudos para caracterização destes valores.

\section{MATERIAIS E MÉTODOS}

Foram utilizadas amostras do aço elétrico de grão orientado com 3,2 \% de silício, retirado após laminação a quente de acabamento em laminador tipo Steckel da Aperam South America, em Timóteo - MG. As amostras foram preparadas e cortadas em forma de corpos de prova para realização de ensaios de tração em altas temperaturas, conforme dimensões estabelecidas pela norma ASTM-E08. 
Através do software Thermo-Calc, foi definido o diagrama de fase para o aço de interesse. Para o esboço do diagrama, o software permite a entrada dos teores dos principais elementos químicos e a faixa de temperatura desejada. Pode-se determinar a variável desejada para cada um dos eixos do diagrama, como temperatura, porcentagem de uma determinada fase, teor de um elemento químico, entre outras.

A quantidade de testes a serem realizados por temperatura foi determinada considerando um nível de confiança de $90 \%$ e um erro próximo de quatro pontos percentuais $(4,2 \%)$. Sendo assim, dado a estimativa de desvio padrão da população pelo desvio padrão da amostra, determinando que o número de testes $(\mathrm{n})$ seria maior ou igual ao valor de $n$ (Equação 1).

$$
n=\left(\frac{t_{\alpha / 2} . S}{E}\right)^{2} n=\left(\frac{t 0,025 ; 4 \times 4,17}{4,2}\right)^{2} n=\left(\frac{2,776 \times 4,17}{4,2}\right)^{2} n=4,002
$$

Foram realizados ensaios de tração nas temperaturas de $600,700,800$ e $900^{\circ} \mathrm{C}$ respectivamente. Os parâmetros de teste foram definidos no software de controle da máquina (TEST $X$ PERT II), onde foram definidos a rampa de aquecimento, o tempo de encharque (10 minutos) e as três rampas de velocidade. A primeira rampa foi definida como pré-carga com velocidade de $8 \mathrm{MPa} / \mathrm{s}$, aplicando uma força de $15 \mathrm{kgf}$ com o objetivo de eliminar qualquer tipo de folga que possa existir no dispositivo de fixação do corpo de prova. A segunda rampa definiu a velocidade do teste até se obter o Limite de escoamento (LE) com segurança, sendo essa mantida a uma taxa constante de 0,8 MPa/s. Após atingir-se 1,2 \% de deformação inicia-se a terceira rampa de velocidade, mantendo o ensaio a $15 \mathrm{~mm} / \mathrm{min}$ até sua ruptura. Como o material não apresenta patamar definido de escoamento foi utilizada uma reta paralela a $0,2 \%$ do regime elástico para obter-se o limite de escoamento.

Através dos resultados de limite de escoamento obtidos, foi realizada a extrapolação exponencial para temperaturas mais elevadas, correspondendo assim os valores de processamento a quente. Finalmente os resultados foram comparados aos valores de tensão utilizados durante processo de laminação, verificando se em algum momento do processo, o limite de escoamento da tira é superado. Para ilustração da deformação sofrida pelo aço durante os ensaios, foi realizada análise da microestrutura após o ensaio de tração, nos corpos de prova em cada temperatura, na região próxima a fratura.

\section{RESULTADOS E DISCUSSÃO}

\subsection{Diagrama de Fases}

Foi obtido o diagrama de fase (figura 1), através do software Thermo-Calc, baseando-se na composição química da amostra e em equações termodinâmicas. Para isto foi utilizada a composição química real do material (tabela 1).

Tabela 1. Composição química do aço elétrico GO.

\begin{tabular}{ccccccc}
\hline Elementos & Si & C & Mn & S & Cr & Ni \\
\hline Composição (\%) & 3,1679 & 0,0391 & 0,0574 & 0,0311 & 0,0252 & 0,0095 \\
\hline
\end{tabular}




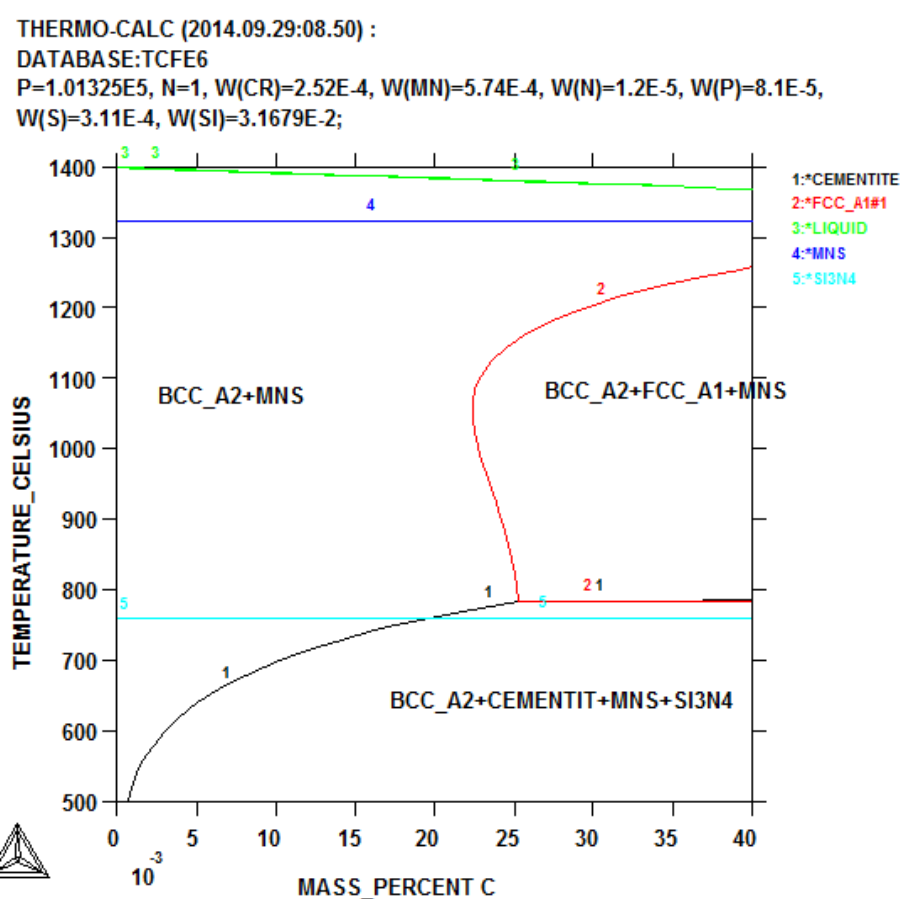

Figura 1. Diagrama de equilíbrio de fases do aço elétrico GO.

Entre as temperaturas de 600 e $700{ }^{\circ} \mathrm{C}$ a aço é processado no campo ferrítico (estrutura CCC), enquanto que nas temperaturas de 800 e $900^{\circ} \mathrm{C}$ o material está em um campo bifásico, contendo ferrita e austenita (CCC e CFC). O processo de laminação a quente do GO ocorre em temperaturas entre 1100 a $950^{\circ} \mathrm{C}$, e dessa forma a deformação ocorre em campo bifásico (ferrita e austenita).

\subsection{Curvas Tensão x Deformação}

Foram obtidas, através dos ensaios de tração em alta temperatura, as curvas carga $x$ deformação, representadas pela figura 2 .

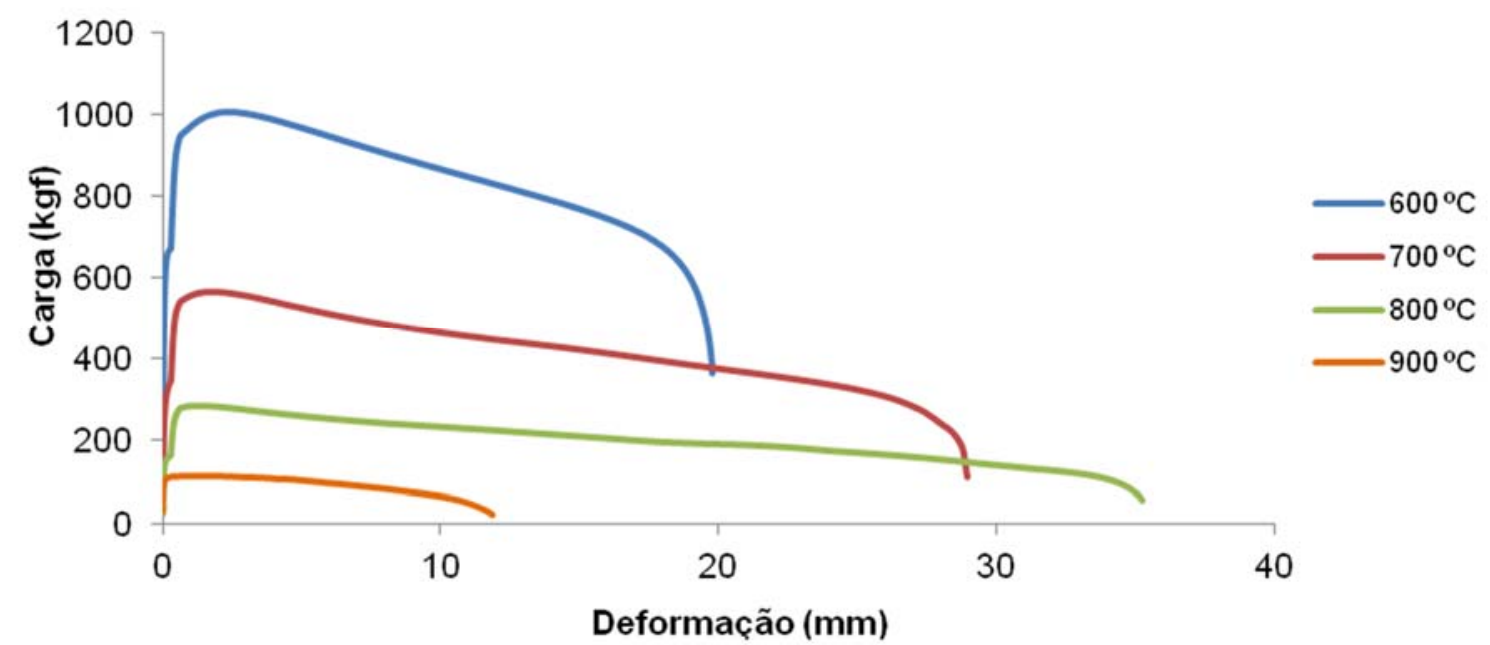

Figura 2. Curvas carga $x$ deformação, conforme temperatura de teste.

As curvas mostram a deformação sofrida pelo aço para cada temperatura de teste. É observado que a medida que a temperatura de teste aumenta o limite de escoamento diminui, e como consequência o aço tem sua ductilidade aumentada. 


\subsection{Variação do Limite de Escoamento Conforme Temperatura}

Os valores de tensão de escoamento, correspondentes às cargas encontradas na figura 1, foram calculados conforme a área do corpo de prova ensaiado. Valores nos quais respeitam a uma tendência exponencial em relação a temperatura.

Os valores de tensão de acordo com a variação da temperatura podem ser observados na tabela 2 .

Tabela 2. Valores de tensão de escoamento obtidos

\begin{tabular}{ccccc}
\hline Temperatura $\left({ }^{\circ} \mathrm{C}\right)$ & $\mathbf{6 0 0}$ & $\mathbf{7 0 0}$ & $\mathbf{8 0 0}$ & $\mathbf{9 0 0}$ \\
\hline Limite de escoamento (Mpa) & 220,75 & 119,22 & 58,30 & 36,45 \\
\hline
\end{tabular}

A figura 3 representa graficamente os valores obtidos, gerando a equação de tendência exponencial referente aos valores encontrados e a barra de erros.

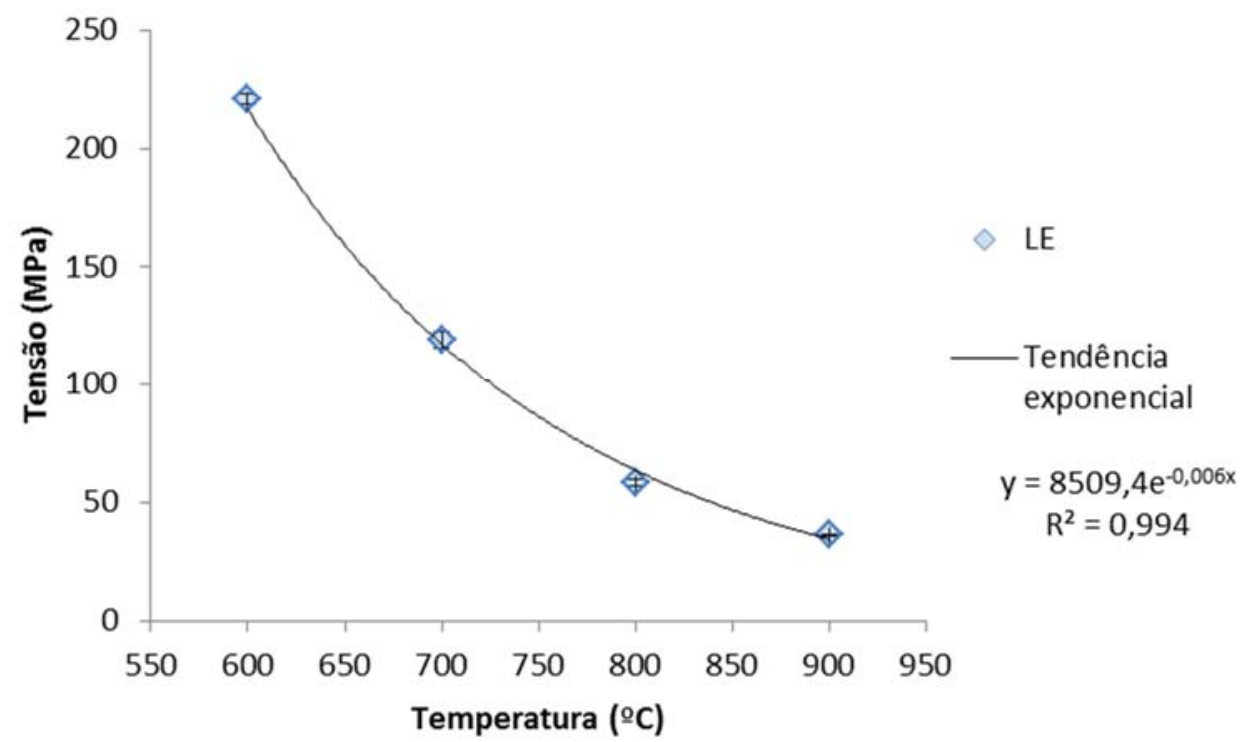

Figura 3. Variação da tensão de escoamento de acordo com a temperatura.

O coeficiente de determinação $\left(R^{2}\right)$ para a equação é 0,994 , o que significa que há uma forte correlação entre o termo dependente (tensão) e o termo independente (temperatura).

Durante o processo de laminação a quente, a temperatura da tira ultrapassa $900{ }^{\circ} \mathrm{C}$, portanto, para verificar as tensões de escoamento correspondentes às temperaturas reais de processo, faz-se necessário o uso da equação de tendência para a extrapolação das tensões de escoamento em temperaturas de processo superiores. A tabela 3 representa os valores de tensão calculados em MPa.

Tabela 3. Valores de tensão calculados através da equação de tendência exponencial

\begin{tabular}{|c|c|c|c|c|c|c|c|c|c|c|c|c|}
\hline $\begin{array}{c}\text { Temperatura } \\
\left({ }^{\circ} \mathrm{C}\right)\end{array}$ & 850 & 920 & 940 & 950 & 960 & 980 & 1000 & 1020 & 1040 & 1060 & 1080 & 1100 \\
\hline $\begin{array}{l}\text { Limite de } \\
\text { escoamento } \\
\text { (Mpa) }\end{array}$ & 1,88 & 09 & 23 & 47 & 81 & 78 & 21,09 & 18,71 & 18,71 & 14,72 & 13,05 & 1 \\
\hline
\end{tabular}

Estão representados graficamente na figura 4 os valores de tensão obtidos nos ensaios e pelo cálculo da tendência exponencial. 


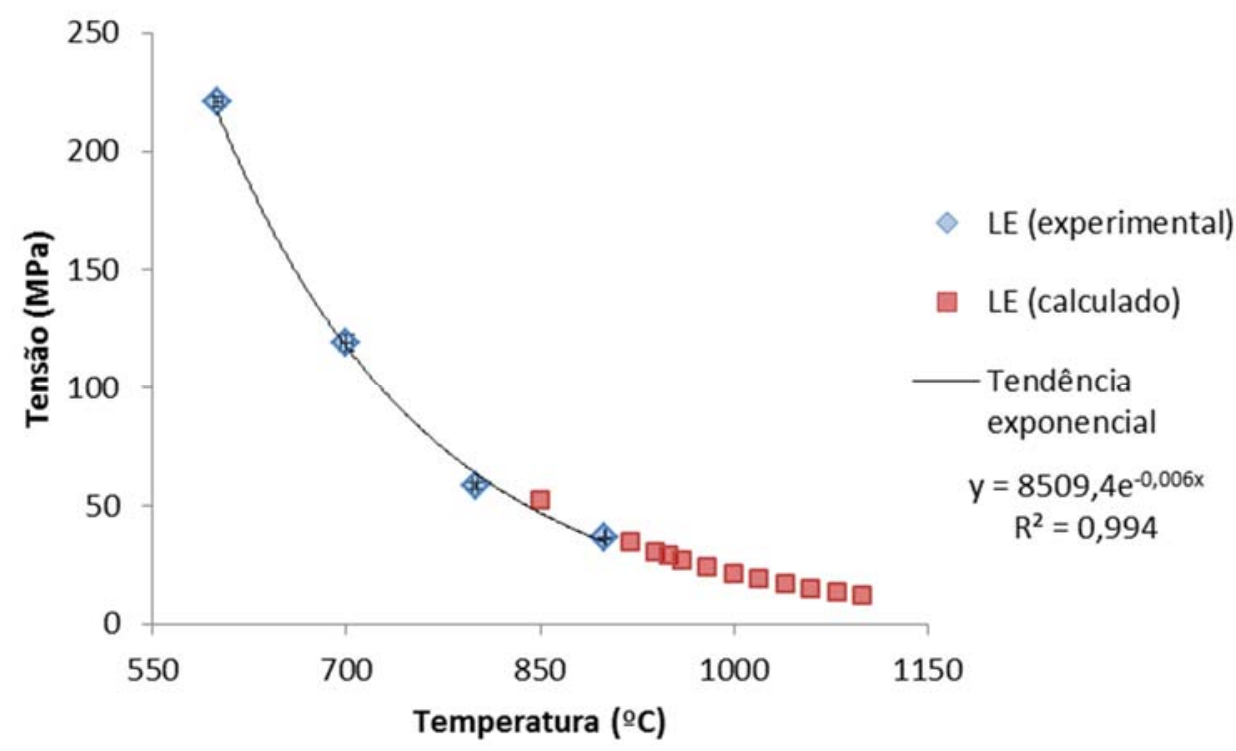

Figura 4. Variação da tensão de escoamento de acordo com a temperatura.

\subsection{Avaliação do processo de laminação no Steckel conforme tensão de escoamento}

O aço elétrico GO é produzido em cinco passes no processo de laminação a quente. Foi verificado para cada passe a tensão real (avante e a ré), das bobinadeiras utilizadas durante processo de laminação no laminador Steckel (na tabela denominada também como Steckel), comparando-as com a tensão de escoamento calculada para este aço. Para isso foram consideradas três regiões para representar o comprimento da tira, sendo elas início, meio e final, devido ao gradiente de temperatura durante processo (tabela 4). A tensão de escoamento para cada região da tira foi calculada através da equação exponencial obtida, considerando-se a temperatura real de processo do aço GO, medida em cada passe de laminação.

Tabela 4. Tensões de processo e calculadas.

\begin{tabular}{ccccc}
\hline Passes & Steckel (MPa) & Início (MPa) & Meio (MPa) & Final (MPa) \\
\hline $\mathbf{1}^{\mathbf{0}}$ & 6,38 & 11,74 & 13,64 & 15,37 \\
$\mathbf{2}^{\mathbf{0}}$ & 6,29 & 16,32 & 11,74 & 18,97 \\
$\mathbf{3}^{\mathbf{0}}$ & 9,68 & 22,04 & 12,09 & 23,40 \\
$\mathbf{4}^{\mathbf{0}}$ & 10,31 & 30,29 & 13,64 & 48,07 \\
$\mathbf{5}^{\mathbf{0}}$ & 18,32 & 40,15 & 16,32 & 28,01 \\
\hline
\end{tabular}

Os dados da tabela 4 tratados graficamente são mostrados na figura 5 . O primeiro passe de laminação mostra tensões de escoamento com valores aproximados, sem discrepâncias entre o início, meio e final do comprimento da tira, de forma que a tensão de escoamento das três regiões da tira não ultrapassa as tensões avante e a ré utilizadas no processo. Os passes seguintes evidenciam o aumento do gradiente de temperatura ao longo do comprimento da tira, ao passo que a temperatura do meio sofre poucas alterações. É percebido também que a medida que temperatura das extremidades diminuem, a tensão de escoamento é elevada. 


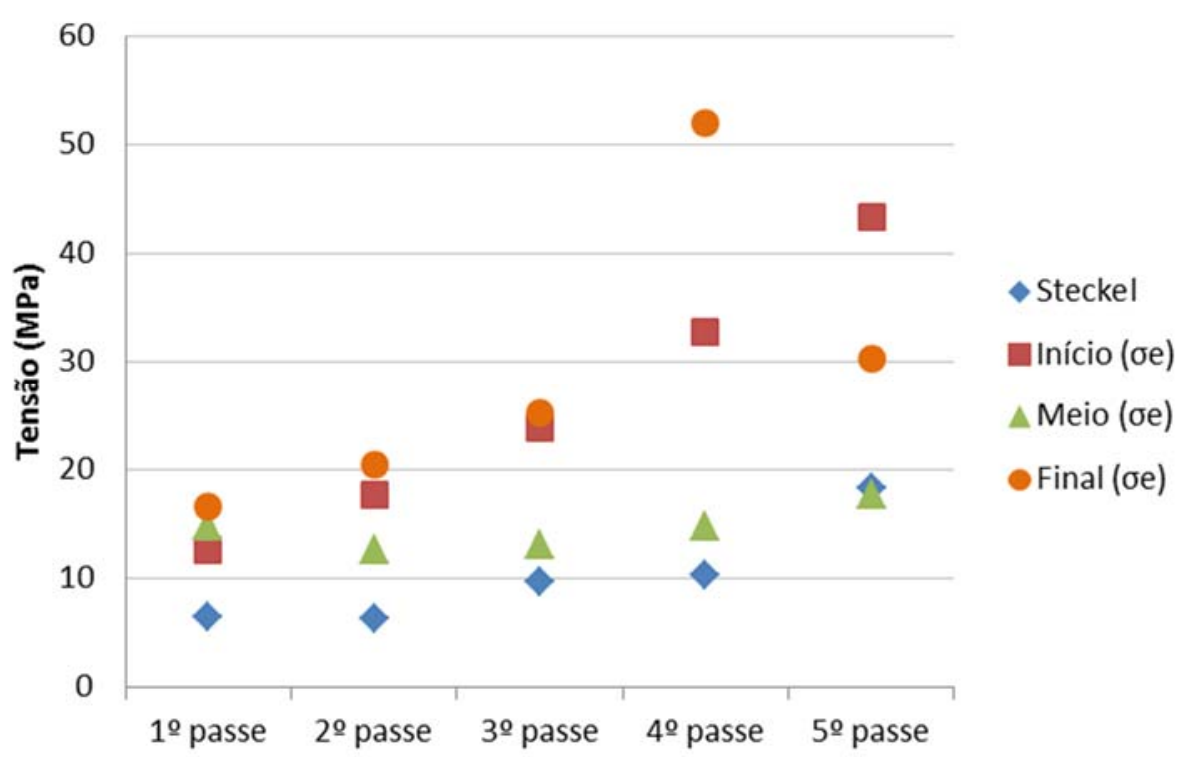

Figura 5. Comparação entre tensão de processo do aço GO e tensões de escoamento.

Durante o processamento do primeiro ao quarto passe, a tensão de escoamento do aço permanece próxima a faixa de tensão de escoamento, sem atingir o limite. No último passe de laminação, entretanto, a tensão das bobinadeiras aplicada ao material ultrapassa seu limite de escoamento, passando assim para o regime plástico. Dessa forma, o material passa a ser deformado não só pela força aplicada pelos cilindros de laminação, mas também pelas tensões avante e a ré, causando estiramento (estreitamento localizado da largura da tira).

Para que a tira possa ser laminada sem causar estreitamento de sua largura, as tensões avante e a ré devem obedecer a tensão de escoamento do material, de forma que sejam aplicadas tensões menores que este valor. Para tal, dever ser considerada a região que apresenta temperaturas mais elevadas durante 0 processo, no caso, o meio da bobina. Isto dever ser levado em consideração, uma vez que as tensões em laminadores tipo Steckel permanecem constantes durante o processo de cada passe.

\subsection{Microestrutura Após Ensaio}

O aço elétrico GO possui uma constituição ferrítica, e estrutura cristalina cúbica de corpo centrado (CCC). Após processo de laminação a quente, este aço possui microestrutura característica, com grãos alongados no centro e recristalizados nas bordas.

As figuras 6, 7, 8 e 9 mostram a microestrutura do aço após a deformação nas temperaturas de $600,700,800$ e $900^{\circ} \mathrm{C}$ respectivamente, com aumento de $100 x$. É notável o aumento do nível de deformação dos grãos ferríticos a medida que a temperatura de teste é elevada.

Com o aumento da temperatura de teste, o limite de escoamento diminui e a ductilidade do aço aumenta, aumentando também o nível de deformação plástica. 


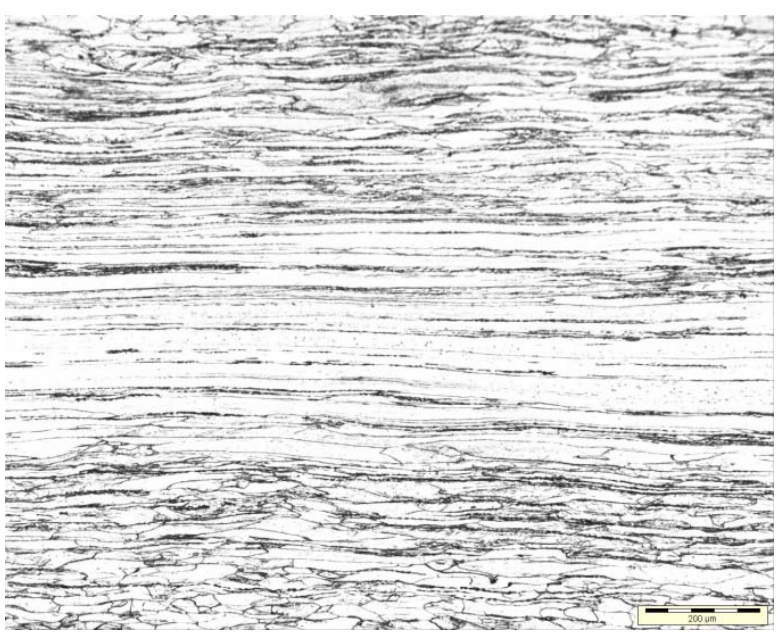

Figura 6. Ensaio realizado a $600^{\circ} \mathrm{C}$.

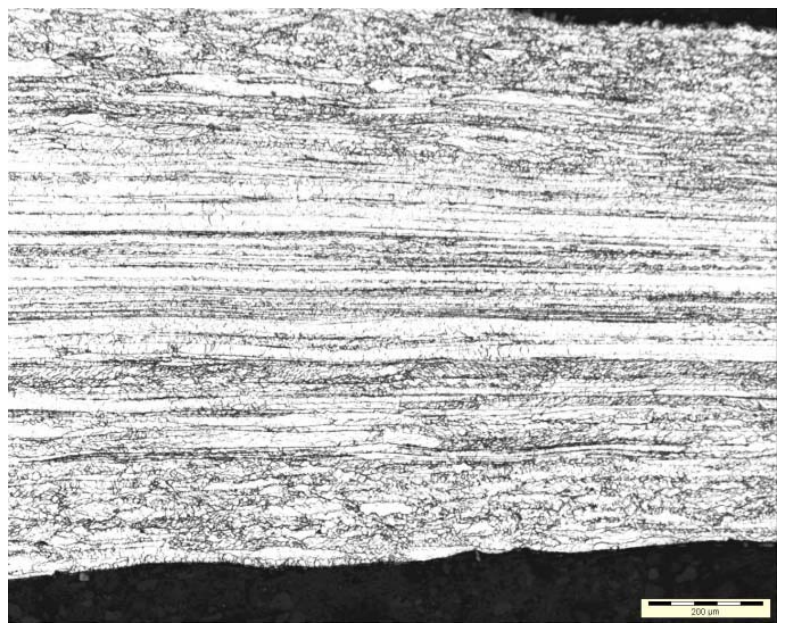

Figura 8. Ensaio realizado a $800^{\circ} \mathrm{C}$.

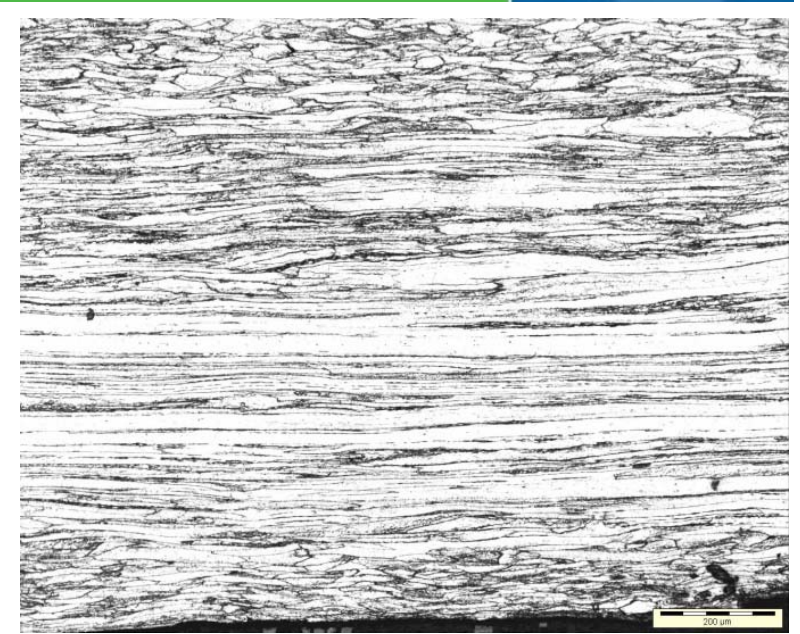

Figura 7. Ensaio realizado a $700^{\circ} \mathrm{C}$.

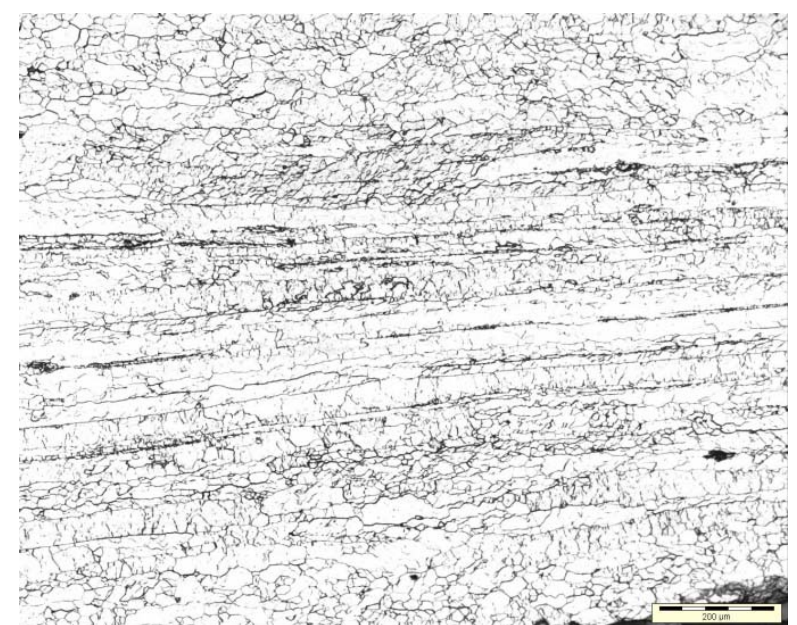

Figura 9. Ensaio realizado a $900^{\circ} \mathrm{C}$.

\section{CONCLUSÃO}

As tensões avante e a ré são imprescindíveis para o processo de laminação, pois facilitam a conformação e reduzem o desgaste dos cilindros. No entanto um cuidado especial deve ser tomado em processos a quente, uma vez que a medida que a temperatura do aço se eleva, o seu limite de escoamento é reduzido.

Ao aplicar tensões de bobinamento e desbobinamento sem o estudo do comportamento do aço em tais condições, a tensão de escoamento pode ser excedida causando defeitos como o estreitamento da largura da tira.

Em relação ao comprimento da tira laminada a quente, a região central alcança temperaturas mais elevadas quando comparada as extremidades da tira, se tornando a região mais susceptível a ocorrência de estiramento. Portanto é local ao longo do comprimento da tira que exige maior atenção durante processo.

Os resultados deste estudo indicam que o processo de laminação a quente do aço elétrico GO, em laminador reversível tipo Steckel, precisa ser adequado conforme as condições suportadas por este aço.

\section{Agradecimentos}

A Aperam South America, unidade de Timóteo em Minas Gerais. 


\section{REFERÊNCIAS}

1 SCHUWARTEN JR, W. Caracterização e Modelagem Matemática da Fração Recristalizada de Ferrita no Aço Inoxidável Ferrítico AISI 430 Durante o Processo de Deformação a Quente em Laminador Reversível Tipo Steckel. Dissertação de Mestrado. Universidade Federal de Minas Gerais, Belo Horizonte, 2007.

2 RODRIGUES, H.C. Simulação em laminador piloto da influência da lubrificação durante o processo de deformação à quente na microestrutura e textura do aço inoxidável ferrítico AISI 430. Dissertação de Mestrado. Universidade Federal de Minas Gerais, Belo Horizonte, 2008.

3 JORGE JR, A.M. Análise do comportamento mecânico dos aços inoxidáveis em altas temperaturas e altas taxas de deformação. Tese de Doutorado. Universidade Federal de São Carlos, São Carlos, 1997.

4 DIETER, G. E. Metalurgia Mecânica. 2. ed. Rio de Janeiro: Guanabara dois; 1981.

5 APERAM SOUTH AMERICA. Documentos Internos. Timóteo, 31 jul. 2014. 